ISSN electrónico: $1885-5210$

DOI: https://doi.org/10.14201/rmc202117293101

\title{
EL MÉDICO (2013): MEDICINA EN LA EDAD MEDIA
}

\section{The physician (2013): Medicine in the Middle Ages}

Emilio PINTOR HOLGUÍN; Nieves MARTínEZ ALSINA; Maria Josefa GUTIÉRREZ CISNEROS; Benjamín HERREROS RUIZ-VALDEPEÑAS

Universidad Europea de Madrid. Facultad de Ciencias Biomédicas. Villaviciosa de Odón (España).

Autor para correspondencia: Emilio Pintor Holguín.

Correo electrónico: emilio.pintor@universidadeuropea.es

Recibido: 13 de mayo de 2020

Aceptado: 19 de mayo de 2020

Publicado: 15 de junio de 2021

\section{Resumen}

En la Inglaterra del siglo XI, un huérfano de 8 años llegará a ser el aprendiz de un cirujanobarbero. Aprende las habilidades básicas de este oficio (sacar dientes, hacer sangrías y pequeñas cirugías) pero no es suficiente. Así que decidirá llegar a ser un médico. Para ello, viajará a Oriente Medio donde se encuentra la más famosa escuela de Medicina. En Persia, logrará entrar como alumno en la madrasa de Ibn Sina (Avicena) donde recibirá una formación teórica y práctica de la medicina, así como de otras disciplinas para lograr ser un médico.

Palabras clave: cirujano-barbero; medicina en la Edad Media; Avicena; peste negra.

\section{Summary}

England, XI century, an 8-year-old orphan becomes a surgeon-barber apprentice. Learning basic skills of this trade (pulling teeth, bloodletting and minor surgeries) but this is not enough. So he decides to become a physician travelling to Middle East, where the most famous medical school of the world was. In Persia, he will be able to enroll as student at Ibn Sina's madrasa (Avicenna) where he will receive theoretical and practical training in medicine as well as other disciplines to become a physician.

Keywords: barber-surgeon; medicine in Middle Age; Avicenna; black death. 
Ficha técnica

Título: El médico.

Titulo original: Der Medicus (The Physician).

País: Alemania.

Año: 2013.

Director: Philipp Stölzl.

Música: Ingo Frenzel.

Fotografía: Hagen Bogdanski.

Montaje: Sven Budelmann

Guion: Jan Berger (Novela: Noah Gordon).

Intérpretes: Tom Payne, Stellan Skarsgard, Olivier Martínez, Emma Rigby, Ben Kingsley, Michael Jibson, Elyas M'Barek, Makram Khoury, Dominique Moore, Fahri Yardim.

Idioma original: inglés.

Color: color.

Duración: 150 minutos.

Género: aventuras, drama.

Productoras: UFA Fiction; ARD degeto; Beta Cinema.

Sinopsis: El médico cuenta la historia de Rob Cole, un niño que se queda huérfano cuando su madre muere de una enfermedad misteriosa en un pueblo minero de la Inglaterra del siglo $\mathrm{XI}$. Con la promesa de convertirse en un médico y vencer a la propia muerte, viaja a Isfahan, en Persia, para estudiar medicina con el gran Ibn Sina. A lo largo de una aventura llena de pruebas y desafíos, su búsqueda incansable de conocimiento le llevará a conocer la amistad y el amor verdadero. El médico es la adaptación cinematográfica del best-seller homónimo de Noah Gordon.

Enlaces:

h t t p s: / / w w w. im d b.com/tit le / tt2101473/?ref_=fn_al_tt_1 https://www.filmaffinity.com/es/film356759. html

Trailer

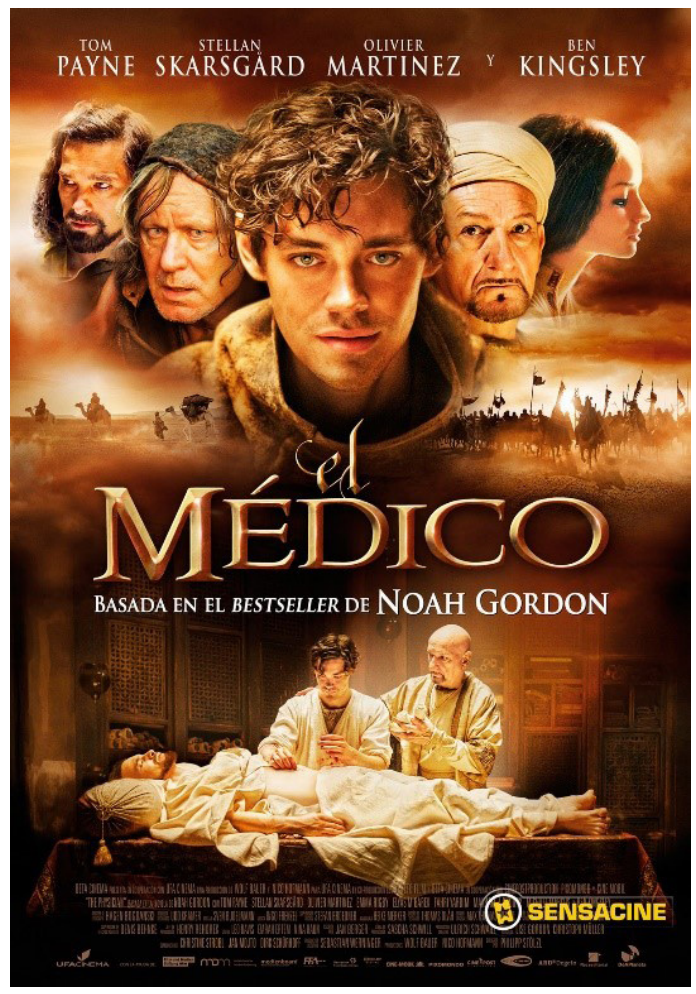

Cartel español.

Introducción

Después de la caída del Imperio Romano, la medicina en Occidente entró en un importante retroceso. La prohibición de los estudios anatómicos en cadáveres determinó que la formación y el desarrollo que tuvo la medicina en el Imperio Romano poco a poco desaparecieran. No existían escuelas para la formación de médicos y la cirugía era considerada como un arte menor que la medicina ${ }^{1}$.

Por el contrario, durante la Edad Media en Oriente ocurrió un fenómeno de extraordinario desarrollo de los conocimientos médicos. Entre los grandes médicos árabes de esa época destacaron especialmente Razhes, Avicena y Averroes². 
Medicina en la edad media en la Europa occidental: el cirujano barbero

En los comienzos del medioevo, Europa sufrió una completa desorganización de la fraternidad médica laica y para cubrir la imperiosa necesidad de asistencia médica apareció la medicina eclesiástica salida de los dispensarios monásticos. Además de la labor asistencial, la medicina monástica tuvo el mérito de reunir los documentos clásicos y evitar que los textos de Hipócrates y Galeno fueran destruidos. Sin embargo, dado que poco a poco los monjes se dejaban llevar por la creciente demanda médica y abandonaban sus deberes religiosos se produjo una discusión que estuvo presente en tres concilios: Reims (1131), Tours (1163) y París (1212). Las conclusiones fueron drásticas, se prohibió a los monjes realizar cualquier práctica médica y, en especial, la cirugía. Esta sentencia se vio reforzada en el siglo XIII ante la aparición de dos órdenes (dominicos y franciscanos) hostiles a la actividad científica. A partir de ese momento la medicina dejó de enseñarse en los monasterios².

Por su profesión, los barberos estaban autorizados a entrar en los monasterios ya que en esa época a los monjes les estaba prohibido usar barba y, además, muchas de las órdenes monásticas debían llevar un corte de pelo especial que las distinguía de las otras; esta íntima relación entre monjes-cirujanos y barberos hizo que estos últimos se convirtieran en asistentes de los primeros en determinados procedimientos operatorios; con el tiempo aprendieron a realizarlos, de tal manera que resultaron los herederos lógicos del oficio, transformándose en barberos-cirujanos ${ }^{3,4}$.

Tradicionalmente, los barberos, como su nombre indica, trabajaban únicamente la vertiente higiénica, con lavado, corte y peinado de cabellos o rasurado de barbas. Sin embargo, con el tiempo incorporaron a su oficio el ejercicio de diferentes actividades médicas como la extracción de dientes, pequeñas operaciones de cirugía (muy frecuente la sutura de heridas), reducción de fracturas y luxaciones y, sobre todo, la flebotomía o sangría terapéutica, acción muy habitual desde el siglo IX, que comenzarían a poner en práctica, por lo que se acuñaría el concepto del cirujano-barberos ${ }^{5,6}$. Algunas de estas actividades están reflejadas en la película (Fotos 1,2 y 3). No existían tampoco escuelas para la formación de estos cirujanos barberos y la transmisión era oral y práctica a los aprendices.

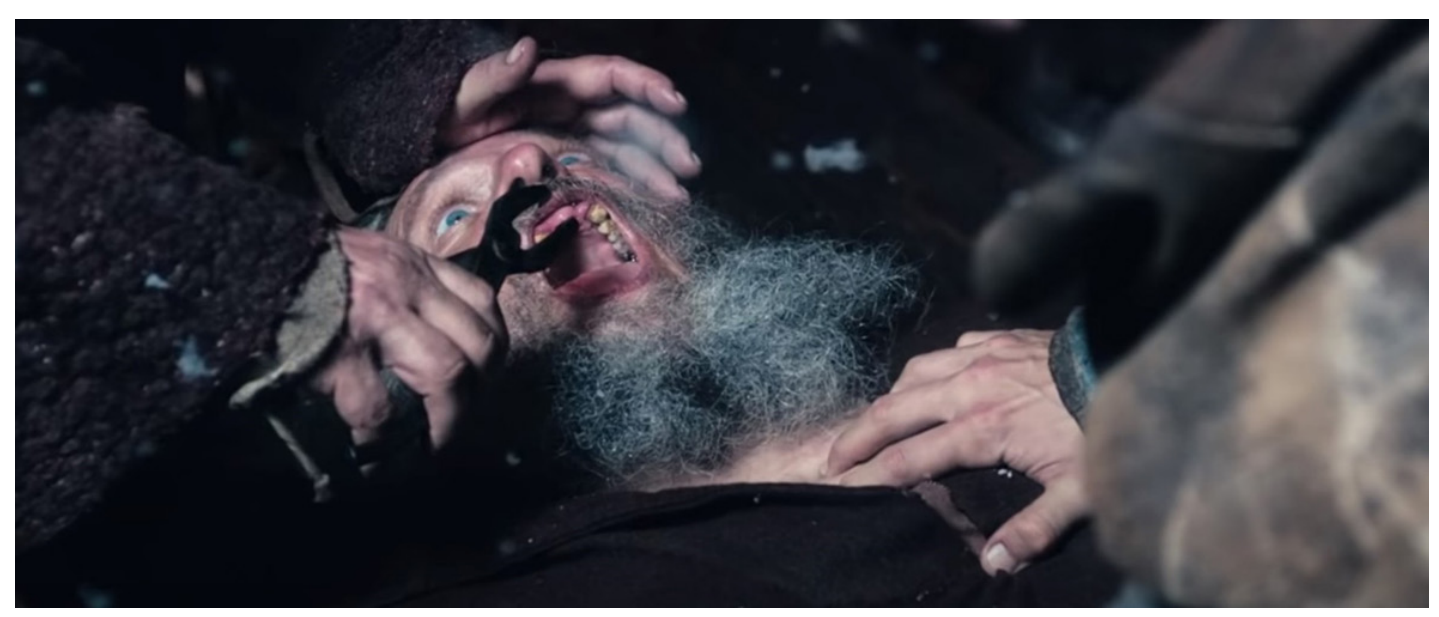

Foto 1. Extracción de piezas dentarias 

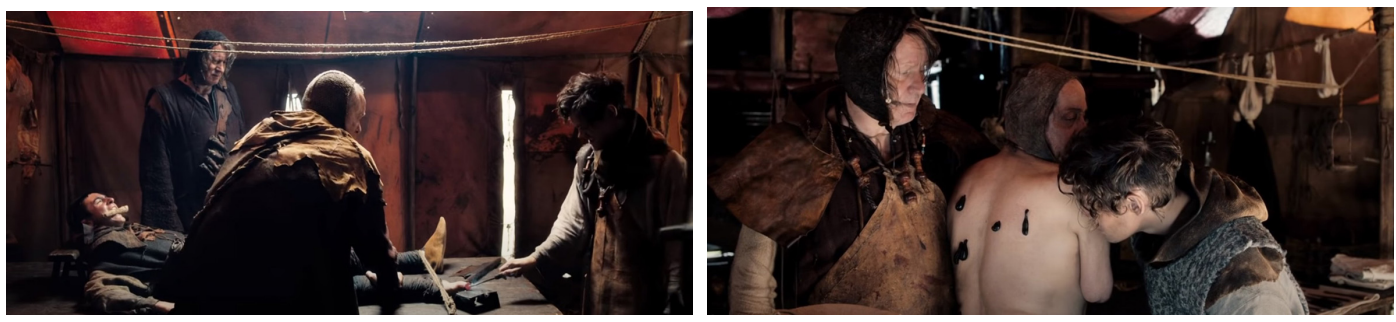

Foto 2 y 3 . Amputación con posterior cauterización (a la izquierda). Sangría empleando sanguijuelas (a la derecha).

\section{Avicena: medicina en el Islam}

Mientras la Europa cristiana se encontraba sumida en las tinieblas de la ignorancia, la medicina árabe disfrutaba de una etapa de esplendor científico. Los tres médicos más destacados de este período histórico fueron Rhazes, Avicena y Averroes. Los dos primeros realizaron su ejercicio profesional en Persia y el último en el califato de Cordoba².

En la película se narra la formación del estudiante de Medicina en el siglo XI en una madrasa persa regentada por uno de los mayores referentes de la medicina islámica: Ibn Sina o Avicena, conocido como el "príncipe de los médicos».

Avicena nació en el año 980 de nuestra era en la población de Afshana en la zona de Asia Central que en esa época pertenecía a Persia y que en la actualidad es parte de Uzbekistan. Aunque se formó en múltiples disciplinas como la geometría, el derecho, la música o la filosofía; escribiendo diferentes tratados en estas áreas, al final se dedicó fundamentalmente al ejercicio, estudio y enseñanza de la medicina. Escribió diferentes tratados relativos a la práctica médicas, el más importante de los cuales es el "Canon de medicina», una obra de 50 volúmenes en la que aborda la teoría médica. Se estima que contiene, aproximadamente, un millón de vocablos, y fue el tratado médico que mayor influencia tuvo hasta el siglo XVIII7,8. En un grabado del siglo XV podemos observar los tres médicos más importantes de la historia hasta ese momento: Hipócrates, Galeno y Avicena. (Foto 4)

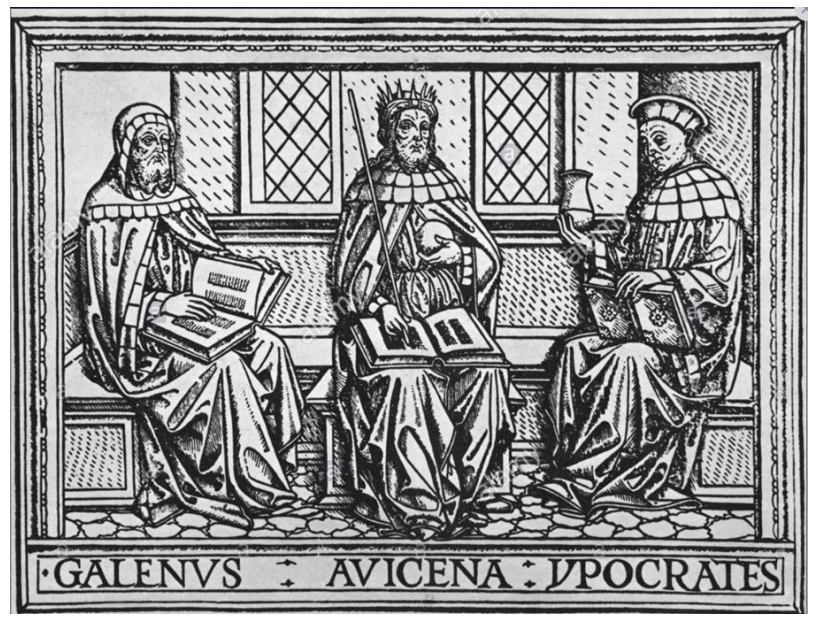

Foto 4. Grabado del Renacimiento donde se representan los 3 referentes médicos de la antigüedad: Hipócrates, Galeno y Avicena. 
En la película, se refleja visualmente como era la formación del estudiante de Medicina en una madrasa del siglo XI en Oriente Medio. En este caso era la madrasa de Isfahan; en Persia, de la cual Avicena era el director (Foto 5 y 6). En la formación del futuro médico eran muy importante el estudio a partir de los clásicos
(Aristóteles, Hipócrates y Galeno), así como la docencia a "la cabecera de la cama del enfermo». Como decía Aristóteles: «No tratamos enfermedades, tratamos personas que padecen enfermedades». No solo recibían formación en Medicina sino en otras disciplinas (Filosofía, astrología, etc.).

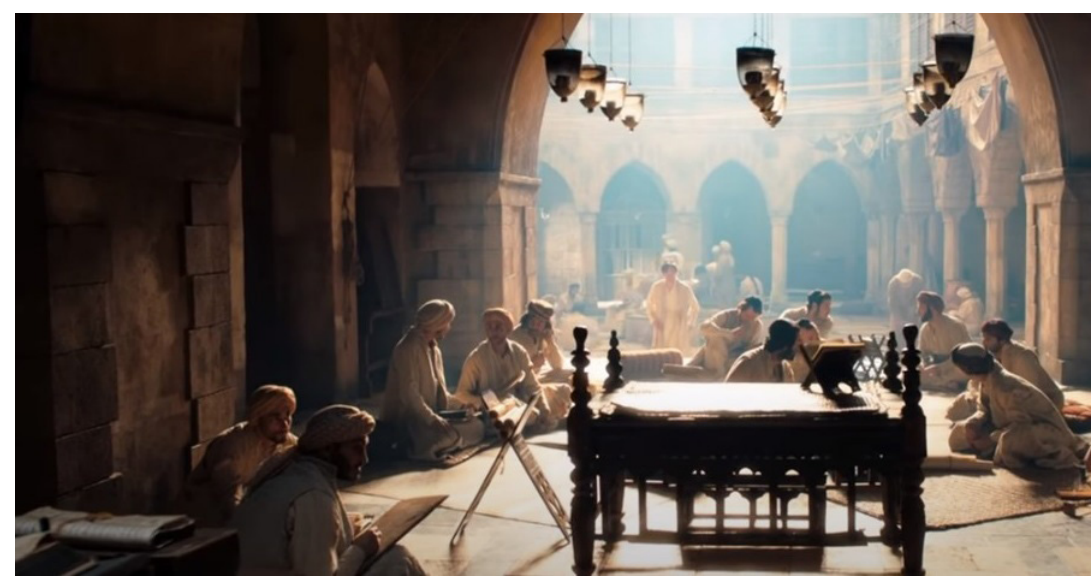

Foto 5. Imagen de una clase en la madrasa de Isfahan.

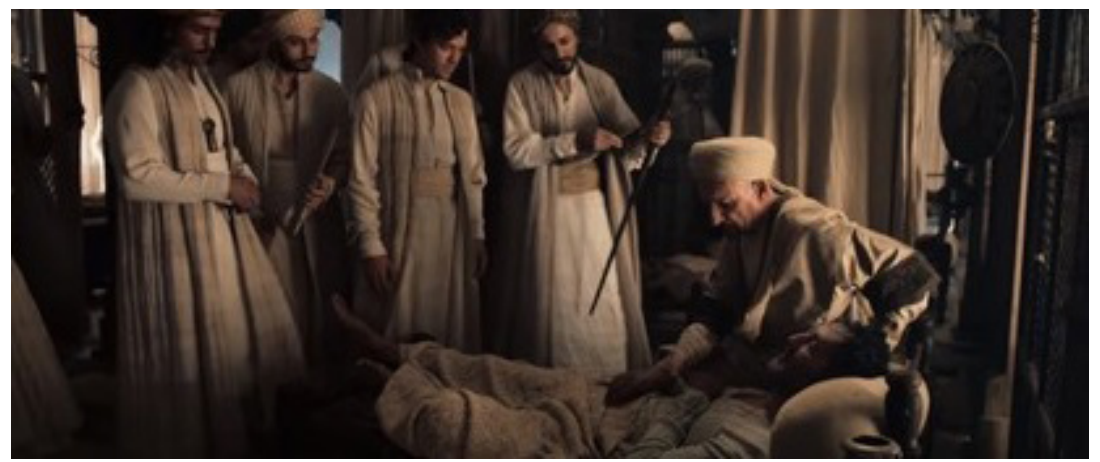

Foto 6. Ibn Sina explicando a la cabecera de la cama del paciente la patología del enfermo.

Aunque en la película se representa al protagonista Rob Cole realizando la disección de un cuerpo humano (Foto 7), a pesar de la negativa de su maestro. Es denunciado por nigromante; un delito muy grave para la ley de Ala y condenado a muerte. Hay controversia en la literatura en relación a si Avicena realizó directamente o no disecciones en humanos ${ }^{9}$. 


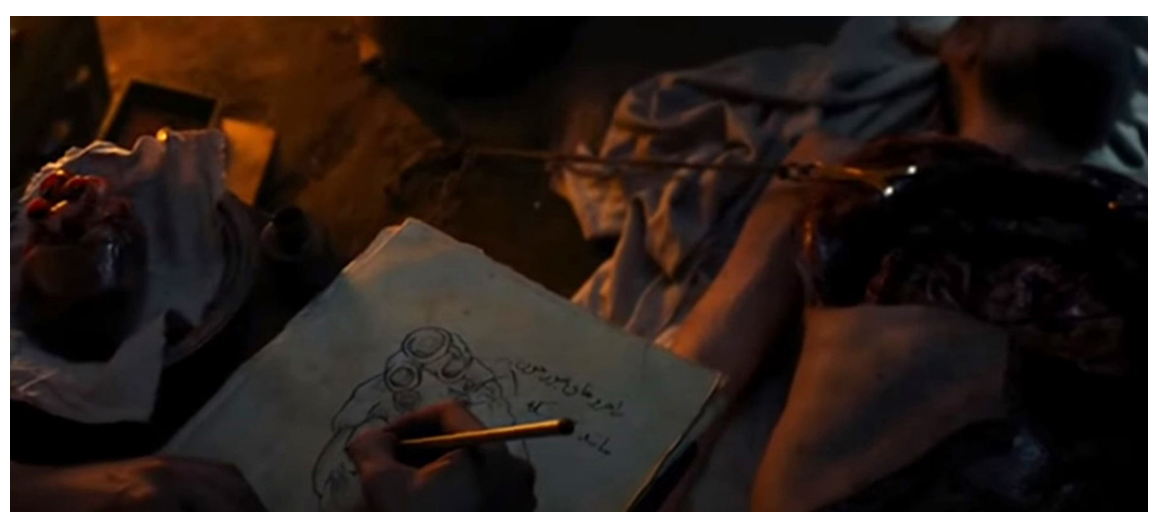

Foto 7. Rob realizando dibujos sobre una disección humana.

\section{Enfermedades de la Edad Media}

En la película se habla entre otras de 3 enfermedades: "La enfermedad del costado", las cataratas y la peste negra.

"La enfermedad del costado" aparece al principio y al final de la película. Al principio como causa de muerte de la madre del protagonista; $y$ una de las causas que Rob quiera ser médico, y al final quien lo padece es el Sha de Persia Ala ad-Daula. Esta entidad se ha relacionado con la apendicitis aguda. En la época que transcurre el film; siglo XI, se desconocía el apéndice ni sus enfermedades.

Cuando el Sha padece "la enfermedad del costado", el protagonista decide hacerle una cirugía abdominal; supuestamente una apendicectomía (Foto 8). El apéndice fue descripto por Berengario Da Carpi en el año 1521, aunque se observó claramente en las descripciones de anatomía de Leonardo Da Vinci, hechas en 1492, pero fueron publicadas en el siglo XVIII. También se encuentran en ilustraciones de Andreas Vesalius en su libro «De Humani Corporis Fabrica» publicado en 1543. Por otro lado, la primera cirugía de apendicectomía fue en 1735 por el Dr. Claudius Amyand fundador del St. George's Hospital y cirujano del Westminster Hospital de Londres. Por tanto, toda esta parte de la trata es totalmente ficción ${ }^{10}$.

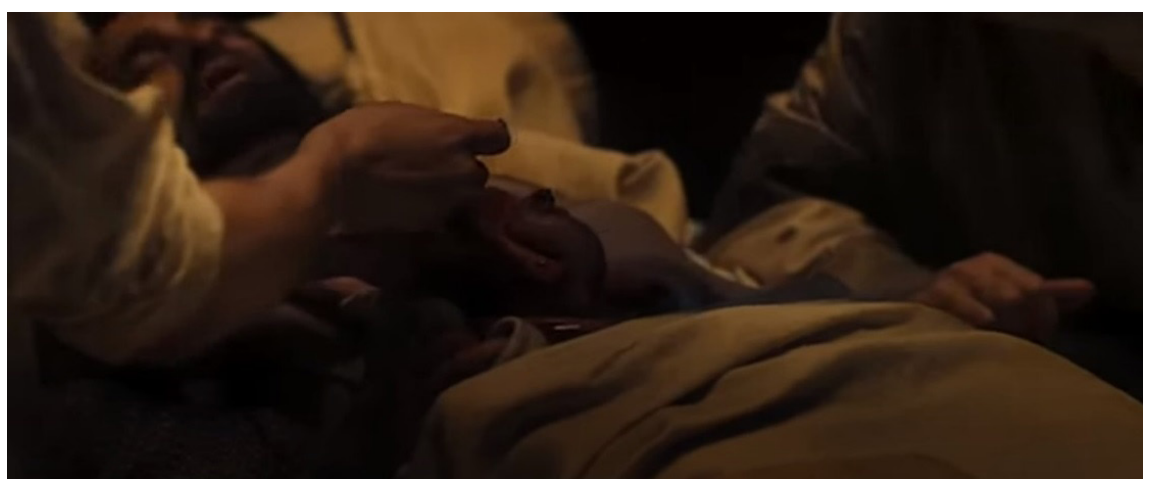

Foto 8. Supuesta apendicectomía en afecto de la «enfermedad del costado». 
En relación con las cataratas, enfermedad asociada a la edad en la que se produce una opacidad del cristalino, en la película el barbero-cirujano protagonista comienza a perder la visión por el desarrollo de cataratas (Foto 9). En el film se muestra el tratamiento quirúrgico de las cataratas por parte de médicos judíos formados en Oriente
Medio. En esa época si se conocía esta patología y se podía realizar el tratamiento quirúrgico. De hecho, Avicena en su Canón tiene un capítulo específico en relación al concepto de catarata así como sus posibles tratamientos, médicos y quirúrgicos, describiéndose la técnica quirúrgica y los cuidados post-operatorios ${ }^{8}$.

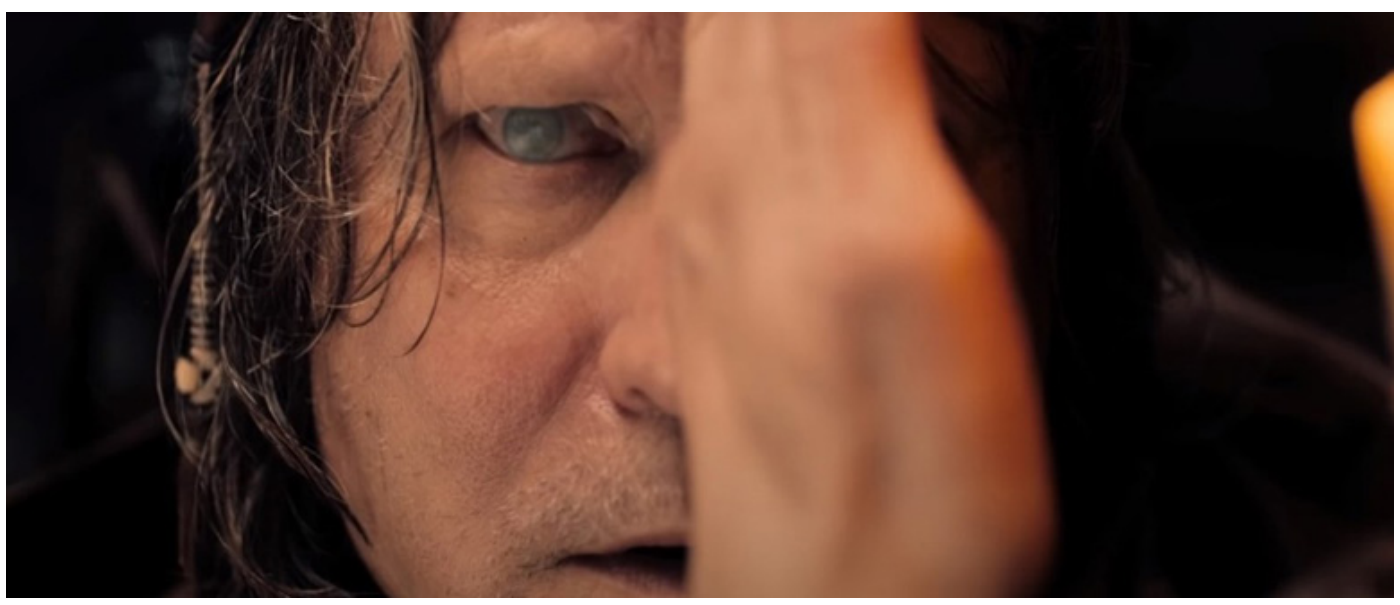

Foto 9. Cirujano-barbero, maestro de Rob Cole, afecto de cataratas.

La peste negra es una infección producida por Yersinia pestis, que fue aislada por vez primera en la pandemia que afectó Asia llegando a Hong Kong en 1894 por Alexandre Yersin. Se adquiere a través de la picadura de la pulga Xenopsylla cheopis, que se encuentra en la rata negra. En humanos, esta infección se puede manifestar de 3 formas clínica diferentes: peste bubónica, neumónica o septicémica. Recibió el calificativo de "negra» porque entre sus manifestaciones estaba la aparición de bubones; grandes adenopatías que producían unas lesiones cutáneas de color azul oscuro que sangraban con facilidad. Sin tratamiento la mortalidad es muy alta.

Aunque esta infección se conoce desde la antigüedad porque producía epidemias localizadas, no fue hasta el siglo VI en que aparece la primera gran pandemia en el Imperio Bizantino: la peste de Justiniano. Posteriormente se hicieron famosas otras pandemias como la que asoló Europa en el siglo XIV; la peste negra, y la pandemia asiática que afectó a China teniendo su epicentro en Hong Kong a finales del siglo XIX ${ }^{11}$.

A lo largo de la historia en la zona de Persia ha habido infinidad de epidemias de peste bubónica ${ }^{12}$. En la Edad Media y durante la vida de Avicena hubo algún brote de peste. De hecho, en su "Canón de Medicina» se describen las manifestaciones clínicas de la peste bubónica7. En la película se refleja un brote de esta enfermedad con su alta mortalidad, su alta contagiosidad y sus manifestaciones clínicas dérmicas. (Foto 10). Aunque en la película el protagonista hipotetiza sobre el origen de la peste en las ratas y en las pulgas de éstas, este hecho científico no se produjo hasta 8 siglos después a finales del siglo XIX ${ }^{11}$. 


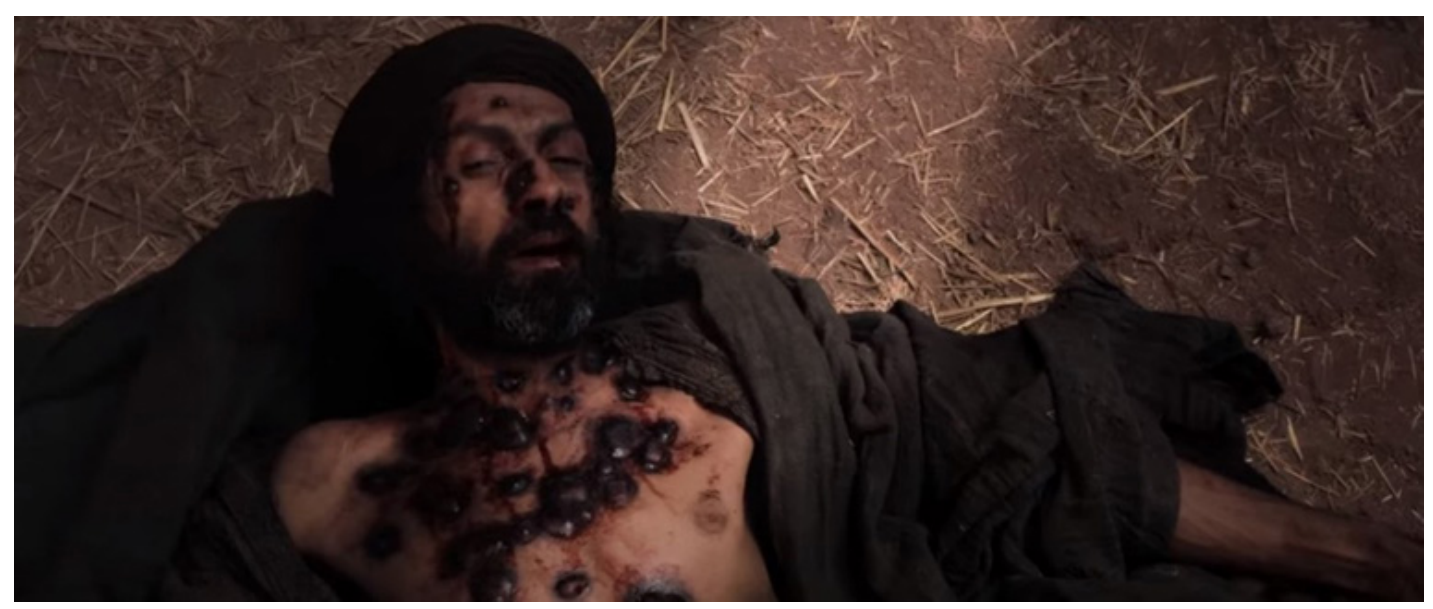

Foto 10. Un paciente afectado por peste negra.

Creemos que, aunque contenga errores históricos importantes, puede ser una película útil en la enseñanza en la asignatura de historia de la medicina cuando se habla de la medicina de la Edad Media. También podría utilizarse en la asignatura de microbiología / enfermedades infecciosas para explicar la peste bubónica desde el punto de vista clínico, microbiológico y epidemiológico.

\section{Referencias}

1. Ghosh SK. Human cadaveric dissection: a historical account from ancient Greece to the modern era. Anat Cell Biol. 2015;48:153-69.

2. Gargantilla Madera P. Breve historia de la Medicina. Madrid: Edicciones Nowtilus; 2011.

3. Ferragud C. Los oficios relacionados con la medicina durante la baja edad media en la corona de aragón y su proyección social 1. Anu Estud Mediev. 2007;37(1):107-37.

4. Garza-Villaseñor, L. El origen de tres símbolos utilizados en medicina y cirugía Cirugía y Cirujanos, . Acacdemia Mex Cir. 2010;78(4):369-76.
5. Dobson J. Barber into surgeon. Ann R Coll Surg Engl. 1974;54(2):84-91.

6. Helliwell A, France IN. A shave, a chat, and a bloodletting: two bits. Can Fam Physician. 1999;45:859-66.

7. Pérez J, Armenteros J, Hernandez L. Avicena, príncipe de los médicos. Vida, obra y legado para la medicina contemporánea. Rev Cubana Med. 2018;57(1):6679.

8. Nejabat M, Maleki B, Nimrouzi M, Mahbodi A, Salehi A. Avicenna and Cataracts: A New Analysis of Contributions to Diagnosis and Treatment from the Canon. Iran Red Crescent Med J. 2012;14(5):265-70.

9. Shoja MM, Tubbs RS. The history of anatomy in Persia. J Anat. 2007;210(4):359-78.

10. Young P. La apendicitis y su historia. Rev med chile. 2014;142(5):667-72.

11. Zietz BP, Dunkelberg $\mathrm{H}$. The history of the plague and the research on the causative agent Yersinia pestis. Int J Hyg EnvironHealth. 2004;207(2):165-78.

12. Shahraki AH, Carniel E, Mostafavi E. Plague in Iran: its history and current status. Epidemiol Health. 2016;38:1-12. e2016033. 


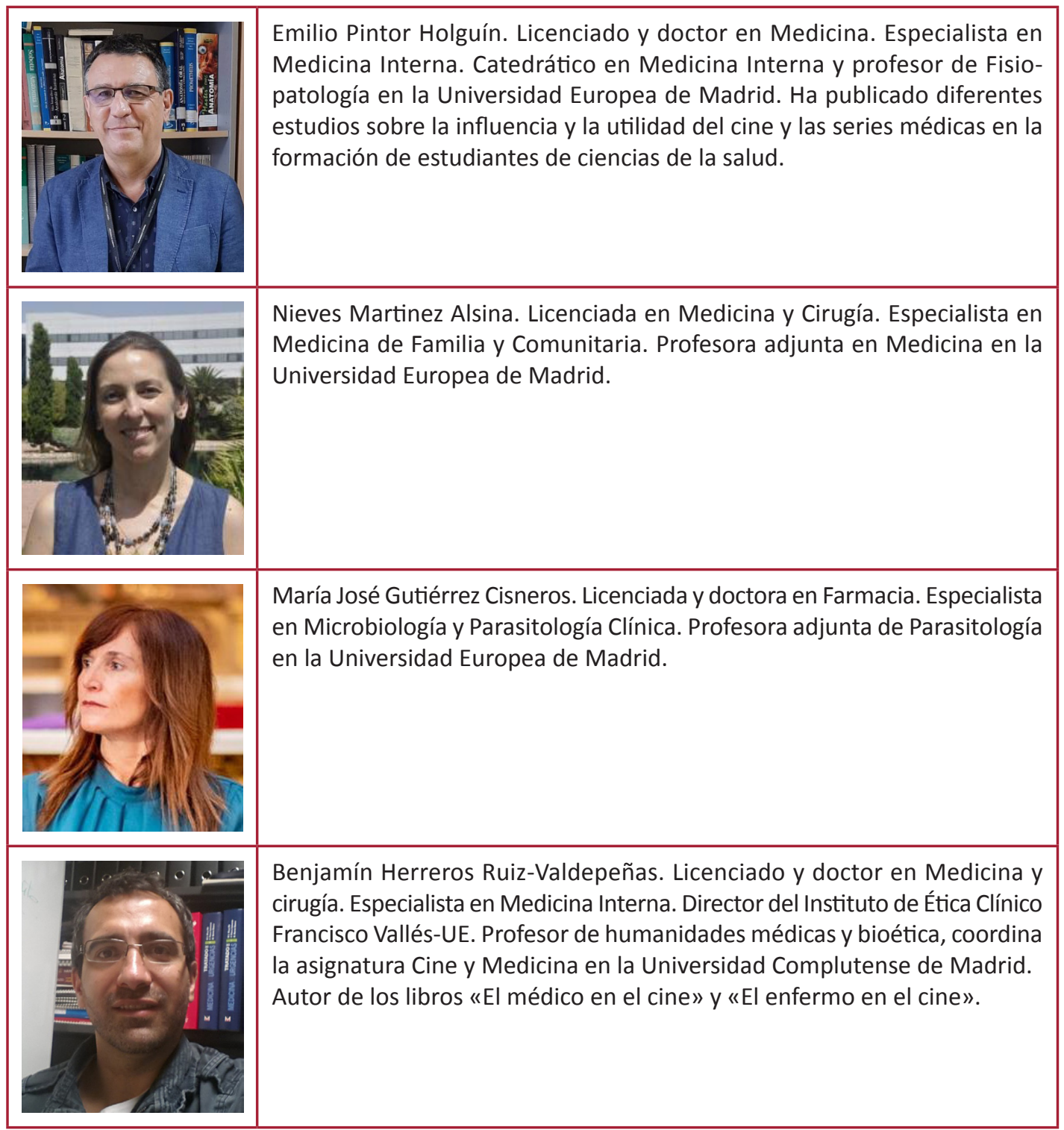

